\title{
Competencies and Development Needs of Physician Managers in Nigeria: A Case Study of Selected
} Hospitals in Ibadan City, Oyo State

\author{
Gbemisola A. Daramola ${ }^{1}$ \& Olawumi D. Awolusi ${ }^{2}$ \\ ${ }^{1}$ University of Roehampton, London, UK \\ ${ }^{2}$ Department of Accounting and Finance, College of Economics and Management, Kampala International \\ University, Kampala, Uganda \\ gbemisola.daramola@roehampton-online.ac.uk, awolusi.olawumi@kiu.ac.ug
}

\begin{abstract}
The physician is traditionally the head of the medical team. To be an effective and efficient team leader is not innate but requires acquiring some competencies. The medical school curriculum was deficient in this regard hence the need for acquisition of these skills through training. Consequently, the present study aims to assess the influence of leadership competencies and Development Needs on the job performance of Physician Mangers. A cross-sectional survey was distributed among Physician Managers in various hospital types that were purposefully selected. Ten Physician Managers were also interviewed for in-depth information of skills they require to perform well. Descriptive and inferential statistics were used to summarize the items of the questionnaire at a 5\% level of significance and to determine if a significant difference existed between groups of Physician managers. Results show that possessing the competencies; communication and relationship management, leadership and business skills and knowledge do influence the job performance of Physician Mangers. There was a significant difference between physicians that had formal training in management and those that had none in the communication and professionalism domains. Seven Physician Managers from different types of hospitals were interviewed, two of them females. They had been in managerial positions from 6months to 34 years. They all emphasized communication and leadership skills as important competencies for every physician manager. They all also suggested that management training must be introduced either during undergraduate or postgraduate training and that physician as head of the medical team require regular management update training.
\end{abstract}

Keywords: Leadership Competencies, Development Needs, job performance, non-parametric test, Physician Managers, Nigeria.

\section{Introduction}

Competencies describe requirements for positions to help improve human performance. In business and human resources, competencies are evaluated and used to determine education and training requirements especially for managers (Matira \& Awolusi, 2020; Mukonga \& Awolusi, 2019). A Medical Doctor/ Physician is one skilled in the art of healing; educated, clinically experienced and licensed to practice medicine. A Manager is one who directs a team or conducts business. According to Stoller, Goodall and Baker (2016) "Physicians used to be seen as ill-prepared for management/ leadership positions but the view is changing? The trio also mentioned that the best two Clinics (Mayo and Cleveland) in America are headed by physicians. In a study by Spehar et al. (2012) physicians were found to be unprepared for the managerial roles but learned management on the fly. Ojo and Akinwunmi's (2015) study suggested "a curriculum review of both undergraduate and postgraduate medical training to include management. In the pre-colonial era, Nigerians relied mainly on traditional medicine. Orthodox health care was provided first to take care of the health needs of British Colonial officers.

The Christian missionaries extended medical services to the people through the establishment of the Sacred Heart Hospital, Abeokuta in 1855 (Schram, 1971). Subsequently, military health facilities were established in Nigeria during the First World War (1914-1918). Many were converted for use by civilians after the war. By Independence in 1960, there were more faith-based hospitals than government-owned. A Chief Medical Officer was then appointed. Training of medical personnel was initially in Britain and then later at the Yaba Medical College, Lagos established in 1939. This facility was shut down after the University College Hospital (UCH) was established in 1948. Other medical schools followed and today there are over 35 medical schools in Nigeria, each using a curriculum developed from that of the University of Ibadan, College of Medicine which they got from the British Medical Education about 70 years ago. However, the College of Medicine, University of Ibadan, my Alma Mata, "reviewed its MB.BS (Bachelor of Medicine and Bachelor of Surgery) and BDS 
(Bachelor of Dental Surgery) curricula to competency-based medical education method of instruction" (Olopade et al., 2016). Traditionally, physicians take a medical history from patients.

Examine them, request for investigations when necessary and interpret the results, make a diagnosis and treat them. They also give counsel on various health issues. However, over the years, the roles and responsibilities of physicians have evolved. Different models of determining physician competencies have been developed and proposed. The Danish Health and Medicines Authority (DHMA) in its 2012 report presented the revised seven roles of physicians. This was done to support the medical competencies acquired during postgraduate medical training. The role here refers to a specific ability or a special competence which a physician demonstrates. There are overlapping roles and no role is superior to the other. These roles are carried out in daily activities and could be done at an individual, organizational or societal level. The roles are interdependent thus a specific competence cannot be assigned to a specific role. "The roles include Medical Expert, Communicator, Collaborator, Manager, Health Advocate, Scholar and Professional" (DHMA, 2012). This model differs from the Canadian model; Canadian Medical Education Directives for Specialists (CanMEDS) with the Medical expert as the central role and others supporting roles. Both models agree that the Medical expert role is what makes physicians who they are and other roles are necessary to perform the role of the Medical Expert.

"Leadership and Management are often used interchangeably but are the same. The former focuses on change/the future while the latter focuses on order and consistency in day-to-day activities" (Feigenbaum, 2017). Medicine is seen as a noble profession and physicians are respected in society. They usually occupy leadership positions in communities, associations, organizations, etc. They are traditionally the head of the medical team. With the global change, so is the "leadership role of physicians changing and becoming more complex. Physicians are being converted to managers" (Adindu, 2013; Bocar, 2013). Patients want better care quality care at lower costs. The physician has a responsibility to deliver this. A study done in 2011 by Goodall (2011) showed that "the top 100 US hospitals in 2009 as identified by the widely used media-generated ranking of quality in three specialties; Cancer, Digestive Disorders and Heart and Heart Surgery. There was a strong positive association between the ranked quality of a hospital and whether the CEO is a physician ( $p>0.001) "$. This is not to conclude that physician leaders do better than non-physician leaders but is consistent with such claims and thus requires further research. "To deliver quality health care, physicians need to begin to take up executive positions in hospital board rooms" (Campbell, 2012).

Being a physician manager involves supervising, planning, coordinating and directing different aspects of a healthy facility e.g staffing, billing, procurement, payments, policy implementation, etc. A physician manager requires a few more skills than his or her clinical acumen. "Managers in any business hold the key to leading other workers to understand the organization's vision. They must be able to communicate effectively, lead and motivate others, multi-task, make decisions and have good business acumen" (Phibbs, 2013). Most physicians are both managers and leaders. According to the World Health Organization (WHO), health is an important cross-cutting policy issue in the international agenda as it is a precondition, an outcome and an indicator of the three dimensions of sustainable development. Members of any society need to be in good health if they are to savor their existence and be fulfilled. However, Nigeria has poor health indices in the Nigerian health sector which is worrisome. The situation is caused by a combination of factors which include inadequate personnel, poor funding, obsolete facilities and equipment and disharmony amongst health professionals all leading to incessant industrial strikes in the sector. Health professionals in Nigeria include; Medical Doctors, Pharmacists, Nurses, Physiotherapists, Medical Laboratory Scientists, Radiologists/ Radiographers, Social care workers, etc.

In 2010, the former President of the Federal Republic of Nigeria, Dr.Goodluck Jonathan directed the then Minister of Health to ensure industrial peace and harmony in the sector. The Minister inaugurated the "Presidential Committee on a Harmonious Work Relationship Amongst Health Workers and amongst Professional Groups in the Health Sector" on 9th August 2010. From an analysis of views expressed in the memoranda submitted to the Committee, it was found that there are an unhealthy rivalry and disharmony among Health Professionals in Nigeria. The key issue is a desire to be the "most important" profession in health care; the struggle for leadership posts in the health care system, and parity in remuneration. This unfortunate phenomenon has eroded the team spirit necessary for effective and efficient health care delivery. 
Lomgurum and Godowoli (2008) confirmed this in a survey of 45 health professionals (15 nurses, 15 pharmacists and 15 physicians). Adindu (2013)'s study on the issue of disharmony among health professionals concluded that "the degree of disharmony among health professionals in the Nigerian health system is censorious". The Nigerian Health sector experienced more than eight industrial actions between 2013-2015 involving physicians, nurses and other health workers (Olatunji, 2013, Hassan, 2013, Olokor, 2013, Obi, 2014, Premium Times, 2014 and Ibeh, 2015).

Such strikes led to avoidable deaths, an increase in quackery activities with complications and medical tourism. Some of these strikes occurred during epidemic outbreaks in the country like Ebola and Lassa outbreaks (Oleribe et al., 2016). Research on 'Industrial action by healthcare workers in Nigeria in 20132015' showed "92\% cited poor healthcare leadership and management as the most common cause of strikes with only $2 \%$ rating the current healthcare management as excellent and $24 \%$ as very good" (Obinna et al., 2016). These incessant strokes occur only in the government-owned hospitals (federal, state, local), not in private hospitals, military hospitals or faith-based hospitals. The Nigeria Health watch on 13th January 2015 wrote an article on how repeated strikes were destroying the public health sector in Nigeria with medical tourism to India on the increase for those who can afford it. Individuals and groups are putting more funds into the private health care sector to improve their quality of health care delivery. In Nigeria, most government-owned hospitals are headed by physicians.

Moka and Ajijola (2017) in their study concluded that "the government policy that conceded or sanctioned the permanent leadership of government hospitals to physicians in a multi-professional environment is globally strange and a major cause of the incessant strikes in the Nigerian health sector. As a physician, I have had confrontations with other health professionals who challenged a decision I took concerning a patient or outrightly refused to carry out a management plan because 'they will not take instructions from a physician'. Consequently, the purpose of this study is to assess the influence of Competencies and Development Needs on the performance of physician managers in Nigeria. However, the following are the specific objectives of the present study:

- To assess the effect of communication and relationship skills of physician managers on their job performance.

- To test the influence of leadership skills on the job performance of physician managers.

- To assess the effect of business skills and knowledge of physician managers on their job performance.

- To assess the effect of the development needs of physician managers on their job performance.

All the objectives above are premised on the fact that most clinical training curricula do not include training in leadership and management skills (Donald, 2013; Lomgurum and Godowoli, 2008). It is therefore important to identify what their peculiar development needs are (Adindu, 2013; Bocar, 2013). Consequently, the study is designed to answer the following questions.

- What is the effect of communication and relationship skills of physician managers on their job performance?

- Is there any significant influence of leadership skills on the job performance of physician managers?

- To what extent is the effect of business skills and knowledge of physician managers on their job performance?

- What is the effect of the development needs of physician managers on their job performance?

Reoccurring comments from other health professionals about physicians are that "doctors are not competent to head health institutions or doctors are bad managers. In a study by Donald (2013) on the "Challenges of Clinical Leadership in Nigeria", he proposed that to achieve high performance in the Nigerian health sector, "physicians must be put at the heart of shaping and running clinical services for excellent outcomes and that this paradigm shift worldwide has led to many competency frameworks, making the concept researchable". The purpose of this study is not to endorse physicians only as the managers of health institutions or as better managers than other health professionals but an inquiry into the competence of physicians to execute managerial duties in different categories of hospitals (public: federal or state, private, faith-based, etc.) in Ibadan city, Oyo state (Goodall, 2011) and to also determine their development needs. An outcome that 
shows most of them as competent can help in boosting the confidence of other health professionals and indeed the general public in the managerial positions held by physicians. Identifying development needs will help in the planning of appropriate training to fill the gaps. These can ultimately lead to better working relationships amongst physicians and other health professionals and an end to strikes in the health sector.

\section{Review of Related Literature}

Conceptual Review: The Nigerian health care system has been bedeviled with many issues from poor health indices (Tandon et al., 2017), low budgetary allocation (Premium Times, 2017), poorly equipped hospitals (Oyekale, 2017), inadequate and under-motivated personnel (Omaswa, 2014) to disharmony amongst different health professionals particularly over leadership in health institutions (Adindu, 2013; Bocar, 2013). However, more than any other issue, in recent years the battle for leadership in the health sector has been the major cause of industrial actions. Specifically, other health care professionals are challenging the managerial roles of physicians in health institutions in Nigeria as they consider them incompetent for the position. The scope and practice of medicine in Nigeria evolved over the years with physicians taking on administrative and managerial roles apart from their professional roles. The lingering crisis in the health workforce is about the biggest constraint to global health system development not only in Nigeria but in Africa as a whole. According to Oleribe et al. (2016), "eight (8) strikes occurred between 2013 -2015 resulting in several avoidable deaths. Healthcare leadership and management issues were named as the most common (92\%) cause of health workers strike as well as the most important (43.3\%)". Traditionally physicians have been responsible for coordinating the activities of the health team to provide quality patient care. However, over the years there is a growing sentiment by health workers that physicians are bad managers (Pharmaceutical Society of Nigeria).

Many critics hinge on the fact that most physicians have little or no training in management. Perry, Mobley and Brubakar (2017) attested that "most physicians in the US are not taught management skills in medical school and receive little on the job training to receive such skills. They are usually elevated into management roles and teamed up with business executives (dyad model)". Indeed some physicians who have held managerial positions did not perform credibly but does this make physicians unfit to be managers? In a review of literature by Loh (2015), it was concluded that there were greater benefits in having physicians in management but they required more training in that area. Stoller, Goodall and Baker (2016) stated that "the best two hospitals in America; Mayo s Clinic and Cleveland clinic according to 2016, US News and World Report (USNWR) ranking have been physician-led for about a century". Clay- Williams et al. (2017) in a review of 16 peer-reviewed studies concluded that "a modest body of evidence supports the importance of including physicians on organizational governing boards". In Nigeria however, the placement of physicians in managerial roles has been alleged by other health workers as 'a design to favor doctors' the protracted supremacy challenge is further deteriorating the already weak Nigerian health system. It is thus a matter of priority to address the leadership tussle by determining if physicians indeed have what it requires and identify skills lacked to perform well enough to stop the bickering.

Competence: Competence is the ability to do something successfully or efficiently. It is a combination of training, experience, skills and knowledge which an individual has and can perform critical tasks. A person $s$ competence should be proportionate to the nature of the job and place of work. Examples of competencies are responsibility, communication, teamwork, decision making, leadership, career motivation, etc.

Assessing Competence: To assess competence refers to a formal process of collecting information on the skills and knowledge a person possesses. Such competence could be attained through on job training, off-job training, a structured learning environment and other relevant work experience. Verification of competency (VOC) should be evidence-based and verified before work commences. "Competency may be verified by:

- Recognition of Prior Learning (RPL): This is an assessment of the skills and knowledge that a worker acquired previously through informal or non-formal training, or through life or other work experiences.

- On-site Recognition of Current Competency (RCC): An assessment of someone who was previously assessed, been deemed competent, and is now required to be reassessed to ensure that competence has been maintained.

- Online training and development program. 
All verification must include a documented assessment" (Oladejo and Awolusi, 2017).

Development Needs: "Development in the context of career development refers to the development of skills and competencies associated with one's profession and position. Assessing development needs is an important part of effective career management. Development needs to change as a person s career progresses and experience grows. Assessment should thus be continuous; gathering and analyzing of information" (Fitzell, 2015). People are found employable based on the skills (competencies) they possess. They may get training while on the job to improve these skills. Whenever there is a gap between the actual and expected level of job performance, there is a development need i.e. a need for training. When an organization identifies the development needs of its employees, an analysis of the training needs is then done. There are different types of needs analysis based on the development that needs to be identified; person analysis, performance analysis, content analysis, organizational analysis, etc. Different techniques can be used to assess needs such as direct observation, questionnaires, interviews, literature review, focus groups, records, etc.

Job Performance: Job performance is defined as the total expected value to the organization of the individual behaviors/ attitudes that an individual carries out within the organization over a standard period (Motowildo and Kell, 2012). Simply, job performance is an assessment of whether a person does a job well. A manager is someone who is in charge of something or a place. The main functions of a manager are planning, organizing, leading and controlling. Managerial skills are similar to leadership skills such as decision-making, problemsolving, communication, planning, delegation and time management. Managers also require these skills as good leaders. There are three levels of management; low level, middle level and top level. Physician Managers are top-level managers that are responsible for overseeing an organization. They develop goals, policies, make decisions and strategize.

Management in Healthcare: The dictionary defines a manager as "a person who is responsible for controlling or administering an organization or a person regarded in terms of skills (competencies) in managing resources". A Physician Manager is simply a physician functioning in the role of a manager. In the traditional model, there is a hierarchical relationship between layers of management, managers and employees. While in the contemporary model managers support and work with other managers and employees.

Theoretical and Empirical Reviews: Physician managers have a responsibility to ensure the health organizations they manage to deliver quality healthcare to the people. To achieve this they depend on management theories relevant to healthcare organizations and hospitals particularly. Some of the theories include:

"Bureaucratic Theory: One of the oldest, it recognizes the three levels of management which also exists in the hospitals. Each member has specific responsibilities based on specific competencies. A physician manager in top-level management has specific roles to carry out and certain competencies are required to do this effectively.

Patient-centered Theory: The focus of healthcare management today is providing patient-centered care. Physician managers as top managers must be able to promote collaboration of all aspects of the hospital to ensure patient-centered care.

Scientific Management Theory: Managers who want specific results adopt this theory. Delegation of authority is to a higher level than bureaucratic theory. The main objective is to improve economic efficiency and in particular labor productivity" (Adindu, 2013).

Evidence-Based Management: According to Dr. David Sackett, "decisions in medical care should be based on the latest and best knowledge of what works" (Pfeffer and Sutton, 2006). This is known as 'evidence-based medicine. Applying this to management, Pfeffer and Sutton (2006) concluded that "managers (like physicians) will practice more effectively if they are routinely guided by the best logic and evidence". Who better to adopt this theory than physician managers? 
Henry Mintzberg Managerial Roles: Professor Henry Mintzberg after studying managers for years concluded that for managers to perform their functions they have to play one of ten roles which have been divided into three groups; interpersonal, decisional and informational (Berg and Howard, 2012; Leedy and Ormond, 2014). A manager thus wears ten different hats at different times depending on the occasion. For physicians to remain relevant in the healthcare system today and in the nearest future, they must be prepared to take leadership and or management roles. Patients expect physicians to be competent and in fact, assume they are regularly assessed. Physicians must have the required competencies to perform well on the job as physician managers. Appropriate training must also be carried out for identified development needs for expected job performance as physician managers. "Responsibilities do not start when physicians assume management positions but the day they take the Hippocratic Oath" (Ojo and Akinwunmi, 2015). Sonsale and Bharamgouder (2017) reported that a " survey showed 85\% of General Practitioners in the United Kingdom felt they did not have the required skills for managerial positions".

Veronesi, Kirkpatrick and Vallascas (2014) found in their study of the English National Health Service that "physicians at board level are positively associated with the financial management of resources and management decision making beneficial for the performance of hospital services. A similar study in Italy National Health Service "showed a negative impact of physician leadership on the efficient management of hospital resources" (Sarto, Veronesi, Kirkpatrick and Cuccurullo, 2014), this suggests a development gap in the physician leadership. The authors in another study by Goodall et al. 2015 highlight how the US's top10 psychiatric hospitals, ranked by the US News and World Report are exclusively managed by CEOs with a medical background due to their competence. Accordingly, Sarto and Veronesi drew some conclusions from their study "first, physicians involvement in strategic decision making is an effective link between strategic planning and its implementation at the clinical level. Secondly, there is quality managerial decision making as physicians understand clinical challenges, a patient needs and knows how best to communicate it to the clinical staff ". These are competencies that aid job performance.

Model for Competency Assessment of Physicians Managers: Health care executives and leaders must have management skills to function maximally in today $\mathrm{s}$ healthcare environment. They are expected to demonstrate measurable outcomes and practice evidence-based management for workplace effectiveness. The Healthcare Leadership Alliance (HLA) comprises six major professional bodies from their research and experiences developed five competency domains common among all practicing healthcare managers.

Identified Competencies and Development Needs of Physician Managers: To meet up with current health demands, physicians require new skills; managerial skills. The skills of being an effective leader and manager are relevant to being a great physician" (Eller, 2017). Ojo and Akinwunmi (2015) reported that "it was pertinent to assess the managerial skill needs of physicians and integrate the findings into the undergraduate and postgraduate medical training curricula". In 2011, Bax, Berkenbosch and Busari carried out research "to identify the specific knowledge, skills and attitudes required for the development of managerial competencies in physicians". They identified residents (physicians in postgraduate training) need for management education by reviewing 40 relevant articles through a PubMed search. However, despite previous studies (Orlando and Hayataian, 2012, and Ackerly et al., 2011) reporting the need for managerial competencies among physicians, published studies assessing these competencies to manage hospital organizations are limited. Rather studies have focused on nursing managers and physician managers together as done by Adindu (2013) and Bocar (2013). On the contrary, many studies have been done to assess the competencies of nurses (Munyewende et al., 2016 and Armstrong et al., 2015).

Compare competencies of physician managers and non -clinical managers. Liu et al. (2016) on the other hand were concerned about developing a competency model for physicians in China. A similar framework was developed by Tuong and Thanh (2017) for public hospital managers in Vietnam. Again several studies have looked at the competencies of physicians in different areas such as Palliative care (Pampuri and 2016), Occupational Health (Lalloo et al., 2016), Public Health (Bertoncello et al., 2015), Radiographers (Mung'omba and Botha, 2017) to name a few but little has been done on the Physician Manager. In 2014, Dias and Escoval did a study to examine the demand for new skills and their influence on both innovation investments and the development of new skills in the public hospital sector in Portugal. The study participants were administrators of hospital management boards which included clinical and non-clinical managers and the 
focus was on organizational rather than individual skills and gaps. Kalhor et al. (2016) studied the managerial competencies of Hospital managers in Tehran, Iran but unlike that of Dias and Escoval, they looked at individual competencies and compared managers in the public and private sectors. Pillay (2010) did a similar study comparing the skills of hospital managers in public and private hospitals in South Africa.

A cross-sectional survey using self -administered questionnaires was done. All the managers have had a clinical background as is the tradition in Iran. A limitation identified by the authors was that the competencies assessed do not reflect the scope of hospital managers. Ireri et al. (2017) compared the experiences, competencies and development needs of doctor managers in Kenya and the United Kingdom. This study put forward that healthcare systems need strong leadership to be sustainable and responsive to the health needs of the future. Qualitative interviews were done in the first stage of the study and a survey of self-administered questionnaires based on the Medical Leadership Competency Framework (MLCF) was used in the second stage. A self-assessed proficiency in different skills was done. "People management, selfmanagement and task-related skills rated highest with largest deficits for the private sector being people management, self-management and health delivery skills" (Pillay, 2010). This study was not specific for physicians and also lacking in covering all the skills required for performance as a physician manager. An earlier study by Pillay (2008) looked at hospital managers in the public sector only with managers reporting they were "most competent in strategic planning, people management and self-management".

Adindu (2013) carried out a study in which hospital managers assessed their performance in Calabar, Nigeria. Of the 260 hospital managers that participated in the study only 35 of them were physicians. Perceived ability to perform in management was generally positive and the author argued that this was not reflective in the Nigerian health situation with poor health indices. Ochonma and Nwatu's (2018) study to assess predictors for management training among hospital managers and chief executive officers in Abuja, Nigeria also had hospital chief executives (C.E.Os) as study participants. It was not clearly stated if these participants were all physicians. This study assessed specifically the training (development) needs of physicians.

\section{Methodology}

Description of the Study Area: Ibadan is the largest indigenous city in West Africa and is located in southwest Nigeria, the capital of Oyo state. It is located $145 \mathrm{~km}$ northeast of Lagos, the commercial capital of Nigeria. According to the 2006 census, central Ibadan has a population of 1,338,659 covering an area of 128 $\mathrm{km}^{2}$. Ibadan is the largest city in Nigeria by geographical area. It is known as the pacesetter state as it is home to many firsts in Nigeria; first skyscraper (Cocoa house), the first standard Nigerian stadium, the first television station in Africa, the first University in Nigeria in 1948 (University of Ibadan) and the first teaching hospital, University College Hospital (UCH) in 1957. The setting was chosen because Ibadan city is a panacea for all health-related issues in Nigeria. This is due to the presence of UCH with some exclusive specialties. According to the Oyo State Hospitals Management Board in 2017, there were 50 state government health facilities of different levels in Oyo state in general with 19 located in Ibadan city. There are over 50 private health facilities and three major faith-based health facilities. There are also educational institution-based health facilities like the University Health Service, University of Ibadan and Military based health facilities like the Military Barracks Hospital, Ojoo Ibadan.

Study Design: This study is a cross-sectional survey in design. The research described Physician Managers s characteristics (competencies and development needs) but not the cause of using qualitative and quantitative methods (Johnson and Christensen, 2012; Odunlami, Awosusi, and Awolusi, 2017). A semi-structured interview was used here as the data to be obtained is highly personalized. The participants in this study were health executives with very busy schedules. Bringing them together for a focus group discussion within the time available for this research was not feasible. In July 2018 a survey was designed adapted from the American College of Healthcare Leadership Alliance (HLA) competencies directory. The directory contained over 80 items for the assessment of physicians thus the need for adaptation. This survey was further modified after pretesting on Physician Managers domiciled in Lagos, a city about $120 \mathrm{~km}$ from Ibadan. The final survey consists of fifty-two questions with thirty-six questions on managerial competencies. Combining both quantitative and qualitative methods in this research helped in providing a better understanding of the research questions as it reduced the limitations of using either of the methods alone. According to Jackson 
(2009) "open-ended questions allow for a variety of responses from participants but are difficult to analyze statistically while the close-ended questions are easily analyzed especially using the Likert scale. Inclusion criteria of Physicians in managerial positions in hospitals are as follows: 1 . the hospital must have at least ten beds and fifteen employees; 2 . The physician must hold or have held a managerial position in a hospital.

However, the exclusion criteria are non-physician managers or hospital administrators. The sample size for this study was determined using the Leslie-Kish formula (Charan \& Biswas, 2013) which states that: $\mathrm{n}=\underline{\mathrm{z}^{2} \mathrm{pq}}$

$\mathrm{d}^{2}$

Where $\mathrm{n}=$ sample size (number of persons required for the study); $\mathrm{Z}=$ confidence interval of $95 \%$ which is equivalent to confidence; Co-efficient of 1.96; $\mathrm{p}=$ proportion of competencies in hospital managers was 92.6\% (Ochonma et al., 2018). The minimum sample size for the quantitative study was therefore 116 respondents Consequently, Physician managers who met the inclusion criteria were purposively selected for self-administration of questionnaires from different types of hospitals: 1. Government-owned: Tertiary, 2. Government-owned: State, 3. Government-Owned: Military, 4. Government-owned: Educational Institution Based, 5. Private and 6. Faith-Based. In choosing participants for the qualitative interview, a purposeful sampling approach was adopted based on the accessibility of the participant and those whose management positions suggested they had a wealth of information that will be beneficial to the study. The number of interviewees was based on saturation. "Saturation is defined as the point at which further data collection offers no new data or sparks no new theoretical insights nor reveals new properties of your core theoretical categories" (Awolusi, 2019; Dworkin, 2012).

Data Collection Instruments and Data Analysis: Questionnaires were delivered by hand to most of the physicians and about ten received them by email. The Quantitative method included the use of selfadministered questionnaires to physician managers. The questionnaire contained 45 close-ended questions that gave quantifiable answers and 4 open-ended questions. The competencies were categorized into five domains within the HLA competency directory which are Communication and Relationship Management, Leadership, Business skills and knowledge Professionalism and Knowledge of the health care environment. For this research, the last domain was not considered as it covers technical skills physicians normally should have acquired from medical training. Data generated for the study were analyzed using Statistical Package for the Social Sciences (SPSS version 20). The HLA competency directory questionnaire used for the study had a Likert scale of a novice, familiar but not competent, competent, proficient and expertly scored as 1, 2, 3, 4 and 5 respectively. The level of competence in each of the domains of the questionnaire was assessed by summing the number of items in each domain of the questionnaire to get a composite score and dichotomized as competent and not competent. To dichotomize the composite score on communication and relationship domain, there are 10 items with a maximum score of 5 points, the maximum obtainable score was $50(10 \times 5)$.

Thus a competent respondent will have a score of 3 for each item in the domain, this implies a score of 30 ( $3 \mathrm{x}$ 10). Hence, respondents with scores less than 30 were categorized as not competent while those with a score of 30 or more were categorized as competent. Similarly, the 9-item responses in the domain of professionalism were summed up to get the composite score in this domain. To dichotomize the composite score on this domain, the 9 items were summed up and a score of 5 for each item in the domain will give a maximum obtainable score of $45(5 \times 9)$. Thus a competent respondent will have a score of 3 for each item in the domain, this implies a score of $36(3 \times 9)$. Hence, respondents with scores less than 36 were categorized as not competent while those with a score of 36 or more were categorized as competent. Also, business skills knowledge competency was assessed using the 9 items in this domain by summing the responses up to get the composite score. To dichotomize the composite score on this domain, the 9 items were summed up and a score of 5 for each item in the domain implies a maximum obtainable score of 45 ( $5 \times 9$ ). Thus a competent respondent will have a score of 3 for each item in the domain, this implies a score of $27(3 \times 9)$. Hence, respondents with scores less than 27 were categorized as not competent while those with a score of 27 or more were categorized as competent. The job performance of the respondents was assessed by summing all the 36 items of the competency part of the questionnaire to get the composite score.

To dichotomize the composite score for the job performance, a score of 5 for each item will give a maximum, obtainable score of $180(5 \times 8)$. Thus a competent respondent will have a score of 3 for each item in the 
domain, this implies a score of 108 ( $3 \times 36)$. Hence, respondents with scores less than 108 were categorized as poor job performance while those with a score of 108 or more were categorized as good job performance. Summary statistics were generated and presented in frequency tables and charts. Normality of the composite scores was tested and the test of normality indicated that the composite scores of all the domains were not normally distributed, thus Mann-Whitney $U$ and Kruskal-Wallis non-parametric tests were used to test for significant difference for variables with two levels and more than two levels respectively. The level of statistical significance was set at 5\%. The qualitative study included interviews of 7 selected physician managers which involved answering open-ended questions. There was 5 face to face interviews and two phone interviews. Recorded data were transcribed and thoroughly read through to identify themes for coding. The American College of Healthcare Leadership Alliance (HLA) competencies directory is a global tool developed in the United States of America for health managers. The adapted format was used in a thesis by Okonkwo et al. 2018 for a Master's degree in Health Services Management at the University of Calabar, Nigeria. The qualitative interview guide was used by Ireri et al. (2017) in a similar study.

Method of Data Analysis: Data generated for the study were analyzed using Statistical Package for the Social Sciences (SPSS version 20). The HLA competency directory questionnaire used for the study had a Likert scale of a novice, familiar but not competent, competent, proficient and expertly scored as 1, 2, 3, 4 and 5 respectively. The level of competence in each of the domains of the questionnaire was assessed by summing the number of items in each domain of the questionnaire to get a composite score and dichotomized as competent and not competent. To dichotomize the composite score on communication and relationship domain, there are 10 items with a maximum score of 5 points, the maximum obtainable score was 50 (10 x 5). Thus a competent respondent will have a score of 3 for each item in the domain, this implies a score of 30 ( $3 \mathrm{x}$ 10).

Hence, respondents with scores less than 30 were categorized as not competent while those with a score of 30 or more were categorized as competent. Similarly, the 9-item responses in the domain of professionalism were summed up to get the composite score in this domain. To dichotomize the composite score on this domain, the 9 items were summed up and a score of 5 for each item in the domain will give a maximum obtainable score of $45(5 \times 9)$. Thus a competent respondent will have a score of 3 for each item in the domain, this implies a score of $36(3 \times 9)$. Hence, respondents with scores less than 36 were categorized as not competent while those with a score of 36 or more were categorized as competent. Also, business skills knowledge competency was assessed using the 9 items in this domain by summing the responses up to get the composite score. To dichotomize the composite score on this domain, the 9 items were summed up and a score of 5 for each item in the domain implies a maximum obtainable score of 45 ( $5 \times 9$ ). Thus a competent respondent will have a score of 3 for each item in the domain, this implies a score of 27 ( $3 \times 9$ ). Hence, respondents with scores less than 27 were categorized as not competent while those with a score of 27 or more were categorized as competent. The job performance of the respondents was assessed by summing all the 36 items of the competency part of the questionnaire to get the composite score. To dichotomize the composite score for the job performance, a score of 5 for each item will give a maximum obtainable score of $180(5 \times 8)$.

Thus a competent respondent will have a score of 3 for each item in the domain, this implies a score of 108 ( 3 $x$ 36). Hence, respondents with scores less than 108 were categorized as poor job performance while those with a score of 108 or more were categorized as good job performance. Recorded data were transcribed verbatim and thoroughly read through to identify themes for coding. Summary statistics were generated and presented in frequency tables and charts. Normality of the composite scores was tested and the test of normality indicated that the composite scores of all the domains were not normally distributed, thus MannWhitney U and Kruskal-Wallis non-parametric tests were used to test for significant difference for variables with two levels and more than two levels respectively. The level of statistical significance was set at $5 \%$. This study followed the ethical principles guiding the use of human respondents in research (Awolusi and Atiku, 2019). Approval for the study was obtained from the Oyo State Ministry of Health Research Ethics Review Committee (AD/13/479/918). The nature, purpose and process of the study were explained to each participant after which informed consent was obtained. Participants were assured of confidentiality, privacy and anonymity of information provided. Necessary steps such as keeping transcripts and data sources in a secured place were taken to ensure confidentiality. Participants were told of the right to withdraw from the 
study at any time. They were also informed of not necessarily directly benefitting from the study but that the data will be used to contribute to better healthcare delivery.

\section{Results and Discussion of Findings}

One hundred and twenty-five (125) questionnaires were distributed, out of which one hundred and five (105) were filled and returned giving a response rate of $84 \%$. Thus the quantitative part of the result is for 105 respondents.

Socio-demographic Data of Physician Managers: Table 1 displays the socio-demographic data of Physician Managers (PM). The majority of them were aged between 46-60 years (58.1\%). In Ireri et al.'s (2017) study where she compared PMs in Kenya and United Kingdom (U.K.), most of the PMs from Kenya were aged between 30-34 years while those in the UK were mostly between ages 50-54 years. In a study of Hospital Managers in Abuja, Nigeria by Ochonma et al. (2018) amongst which $39.4 \%$ were Physicians, the managers were mostly between ages 35-40 years. This suggests there is no specific age bracket when a physician can become a manager. There were more males (79\%) than females $(20.9 \%)$ amongst them. Ireri et al. study showed that $77 \%$ of the Kenyan respondents were males and $81.5 \%$ of the UK respondents were also males. Similarly in the Ochonma et al. (2018) study, 63.5\% were males. Management is one of the most difficult positions for women to compete with their men and the hospital setting is not an exception.

In a study by Tlaiss (2013) in a University hospital, she examined attitudes towards female managers and found that employees and other managers had negative attitudes towards them. The findings in a similar study in Turkey by Kutlu and Akbulut (2018) are similar. These may be associated with a low number of female PMs. Most of the PMs have MBBS (Bachelor of Medicine and Bachelor of Surgery), $75.2 \%$ and MBChB (Bachelor of Medicine and Bachelor of Surgery), 16.2\% which are equivalent degrees awarded depending on the institution. Most of the PMs had their basic medical qualification more than 20 years ago (68.6\%) with only two (1.9\%) attaining basic qualification less than 5 years ago. The majority of the PMs had Fellowships (40.9\%), 18.1\% have a Masters and 13.3\% have a Master's in Public Health (MPH). None of the PMs has a Ph.D. (Doctor of Philosophy) and 8.6\% have no additional qualification to the basic medical degree. Most of the PMs were in Private hospitals (49.5\%) and the government-owned tertiary hospital (23.8\%). Only 3.8\% were in Military hospitals.

Table 1: Socio-demographic Data of Physician Managers

\begin{tabular}{|c|c|c|}
\hline \multirow{2}{*}{\multicolumn{3}{|c|}{$\begin{array}{l}\text { Demographic Variable } \\
\text { Age Group (Years) }\end{array}$}} \\
\hline & & \\
\hline $25-35$ & 1 & 1.0 \\
\hline $36-45$ & 20 & 19.0 \\
\hline $46-60$ & 61 & 58.1 \\
\hline 61 and above & 23 & 21.9 \\
\hline Total & 105 & 100.0 \\
\hline \multicolumn{3}{|c|}{ Sex } \\
\hline Male & 83 & 79.0 \\
\hline Female & 22 & 20.9 \\
\hline Total & 105 & 100.0 \\
\hline \multicolumn{3}{|l|}{ Basic Qualification } \\
\hline MBBS & 79 & 75.2 \\
\hline BDS & 8 & 7.6 \\
\hline MBChB & 17 & 16.2 \\
\hline Bch.D & 1 & 1.0 \\
\hline Total & 105 & 100.0 \\
\hline \multicolumn{3}{|c|}{ Years of Basic Qualification } \\
\hline Less than 5 years & 2 & 1.90 \\
\hline
\end{tabular}




\begin{tabular}{lll}
\hline $6-10$ & 9 & 8.57 \\
$11-15$ & 5 & 4.76 \\
$16-20$ & 17 & 16.2 \\
More than 20 years & 72 & 68.6 \\
Total & 100 & 100.0 \\
& & \\
Additional Qualification & & \\
MBA & 3 & 2.9 \\
MSc & 19 & 18.1 \\
MPH & 14 & 13.3 \\
PhD & 0 & 0 \\
Fellowship & 43 & 40.9 \\
Diploma & 6 & 5.7 \\
Others & 11 & 10.5 \\
None & 9 & 8.6 \\
Total & 105 & 100.0 \\
\hline
\end{tabular}

Hypotheses Testing: Table 2 below displays competence comparison between PMs grouped by their type of formal training in Management. In Communication and Relationship management $(p=0.007)$ and Professionalism ( $p=0.042)$ domains, there is a significant difference between PMs that had some formal training in Management; Certificate, Degree or Diploma programs and those that had none. However, in the Leadership ( $p=0.114)$ and Business Skills and Knowledge $(p=0.256)$ domains, there was no significant difference between PMs that had formal training and those that had none. There was no significant job performance difference of PMs $\mathrm{p}=0.078$ due to the training. This implies that formal training made a difference in the communication and professional skills of PMs. Other results (not shown) further display competence comparison between PMs grouped by their years of experience. In Communication and Relationship management ( $\mathrm{p}=0.490)$, Professionalism $(\mathrm{p}=0.508)$, Leadership $(\mathrm{p}=0.493)$ and Business Skills and Knowledge $(p=0.298)$ domains, there was no significant difference between the three groups of managers; those with less than 5 years experience, those with 6-10 years experience and those with over 10 years experience in management. There was also no significant job performance difference between the three groups of PMs, $p=0.409$. This implies in the four domains competence was the same for the same the three groups of PMs and the same in job performance.

Table 2: Competency Comparison among Physician Managers grouped by Formal Training in Management

\begin{tabular}{|c|c|c|c|c|c|c|}
\hline $\begin{array}{l}\text { Competency } \\
\text { Domain }\end{array}$ & $\begin{array}{l}\text { Formal Training in } \\
\text { Management }\end{array}$ & $\begin{array}{l}\text { Mean } \pm \\
\text { Standard } \\
\text { Deviation }\end{array}$ & $\begin{array}{l}\text { Mean } \\
\text { Rank }\end{array}$ & $\begin{array}{l}\text { Kruskal } \\
\text { Wallis H }\end{array}$ & DF & P-Value \\
\hline $\begin{array}{l}\text { Communication } \\
\text { and Relationship } \\
\text { management }\end{array}$ & $\begin{array}{l}\text { Certificate }(n=25) \\
\text { Degree }(n=5) \\
\text { Diploma }(n=3) \\
\text { Others }(n=26) \\
\text { None }(n=46)\end{array}$ & $\begin{array}{l}41.60 \pm 5.61 \\
36.00 \pm 2.55 \\
42.67 \pm 4.16 \\
36.96 \pm 7.81 \\
37.19 \pm 5.29\end{array}$ & $\begin{array}{l}51.38 \\
29.00 \\
57.17 \\
\\
33.89\end{array}$ & 12.274 & 3 & 0.007 \\
\hline Professionalism & $\begin{array}{l}\text { Certificate }(n=25) \\
\text { Degree }(n=5) \\
\text { Diploma }(n=3) \\
\text { Others }(n=26) \\
\text { None }(n=46)\end{array}$ & $\begin{array}{l}37.44 \pm 5.51 \\
33.80 \pm 2.17 \\
39.67 \pm 1.53 \\
33.77 \pm 7.33 \\
34.37 \pm 5.04\end{array}$ & $\begin{array}{l}47.60 \\
30.10 \\
62.00 \\
35.51\end{array}$ & 8.222 & 3 & 0.042 \\
\hline Leadership & $\begin{array}{l}\text { Certificate }(n=25) \\
\text { Degree }(n=5) \\
\text { Diploma }(n=3) \\
\text { Others }(n=26) \\
\text { None }(n=46)\end{array}$ & $\begin{array}{l}32.06 \pm 6.04 \\
31.00 \pm 5.83 \\
35.00 \pm 1.00 \\
29.00 \pm 6.72 \\
30.09 \pm 4.56\end{array}$ & $\begin{array}{l}45.22 \\
42.60 \\
32-00 \\
34.45\end{array}$ & 5.956 & 3 & 0.114 \\
\hline
\end{tabular}




\begin{tabular}{|c|c|c|c|c|c|c|}
\hline Business Skills and & Certificate(n=25) & $31.44 \pm 8.34$ & 43.00 & 4.046 & 3 & 0.256 \\
\hline \multirow[t]{4}{*}{ Knowledge } & Degree(n=5) & $32.00 \pm 5.87$ & 47.30 & & & \\
\hline & Diploma (n=3) & $35.67 \pm 5.13$ & 58.50 & & & \\
\hline & Others( $\mathrm{n}=26)$ & $28.11 \pm 9.42$ & & & & \\
\hline & None $(n=46)$ & $29.04 \pm 6.88$ & 36.37 & & & \\
\hline \multirow[t]{5}{*}{ Job Performance } & Certificate(n=25) & $142.64 \pm 24.15$ & 47.10 & 6.808 & 3 & 0.078 \\
\hline & Degree $(n=5)$ & $132.80 \pm 14.57$ & 37.10 & & & \\
\hline & Diploma (n=3) & $153.00 \pm 11.79$ & 60.00 & & & \\
\hline & Others $(n=26)$ & $127.85 \pm 29.16$ & & & & \\
\hline & None $(n=46)$ & $130.69 \pm 19.12$ & 35.15 & & & \\
\hline
\end{tabular}

Analysis of Qualitative Data: Six participants participated in this study and the majority (4) of them is males. They are Medical directors of hospitals, consultants, heads of the department and public health physicians. The majority of them had both administrative and clinical duties as their current responsibilities. The clinical duties include patient care, treatment of illnesses, doing a ward round, attend clinical meetings and take part in the medical activities of the hospital. Their duties also involve training and re-training of other cadres. According to one of them, their work is exciting, challenging and dynamic. Impacting on others and are happy from the feedback received to make their work exciting while the administrative part of it make it challenging As was put by him: "It is exciting because there are so many aspects of the job that allows me the opportunity to impact others and when you get the feedback you are happy and excited. Then there are also opportunities to test theories and principles in leadership, and if you get results you are excited. It's stressful because the human aspect of it is a bit challenging. Human beings are what we are; unpredictable.

Of all available resources, human capital is the most intricate. It is dynamics because you keep on operating in an environment of uncertainties. What is good yesterday is no better today. If you have a target, you realized that your target is not a moving target. The environment - business environment is changing. The tools keep changing courtesy technology. The resources also have a huge turnover because people are not at the peak of their careers. So you keep on working with new people, new hands "different political setting", that makes it more dynamic". One participant posits that the best part was when there was funding, positive feedback in terms of knowledge generation and new horizons are coming up. As was put by the participants: "The best part of my job is I have been able to pass on knowledge and satisfaction of mind seeing your patient getting well". "Well the best part was of it was that when we first started the private hospital, it was quite lucrative. The funds were coming in then. But as one got older in it some other things crept in. but by and large, it is still worth what we are doing at least we are happy with it and keep ourselves afloat and abreast of the medical practices". Some of the challenges mentioned by the participants include a shortage of funds, double taxation, borrowing shortage of manpower, high turnover, training and re-training. They get money from the bank, the interest rate is outrageous, and they have to pay it back at a specific charge.

According to them: "Paucity of manpower, we don't have enough, just like most hospitals we don't have enough manpower. The little six participants participated in this study and the majority (4) of them is males. They are Medical directors of hospitals, consultants, heads of the department and public health physicians. The majority of them had both administrative and clinical duties as their current responsibilities. The clinical duties include patient care, treatment of illnesses, doing a ward round, attend clinical meetings and take part in the medical activities of the hospital. Their duties also involve training and re-training of other cadres. According to them: Some of the challenges mentioned by the participants include a shortage of funds, double taxation, shortage of manpower, high turnover, training and re-training. They get money from the bank, the interest rate is outrageous, and they have to pay it back at a specific charge. According to them: "Paucity of manpower, we don't have enough, just like most hospitals we don't have enough manpower. The little we have is overstretched. So I will do what I shouldn't do as Medical Director. You understand. The little we have we give them additional responsibilities, I have to make sure that everywhere is covered".

"The major one is finance. I mean in a private setting the government is not in any way financing any private hospital organization and the task is enormous. Double taxing and you have to pay through your nose for virtually everything, no reimbursement from anywhere that is the major challenge". On their relationship with their colleagues, the majority said they related well with them while one person said they cannot but only 
their colleagues can assess them on the way they see the relationship. They are confident that their colleagues will not score them low. As way being put by them; "From my end, I might say I get along easily with my colleagues. But when need to draw the line I don't hesitate to do that. I don't. I think you have gotten to a forum when they know what I want. That is very obvious because for every leader there comes a time when you are supposed to drive the system where everybody should be able to key into where it's heading to. I think in terms of integrity in terms of fairness, my colleagues will not score me low. They will not score me low". They are also confident that their relationships with other staff are cordial and very good but with the administration, there may be a need for improvement. "With the government, they claimed that they interact by paying their dues, obey the laid down rules and regulation and support the supervisory role by the government. One of the participants said he was not sure if he is friendly with the government".

"The major one is finance. I mean in a private setting the government is not in any way financing any private hospital organization and the task is enormous. Double taxing and you have to pay through your nose for virtually everything no reimbursement from anywhere. That is the major challenge". On their relationship with their colleagues, the majority said they related well with them while one person said they cannot but only their colleagues can assess them on the way they see the relationship. They are confident that their colleagues will not score them low. As way being put by them; "From my end, I might say I get along easily with my colleagues. But when need to draw the line I don't hesitate to do that. I don't. I think you have gotten to a forum when they know what I want. That is very obvious because for every leader there comes a time when you are supposed to drive the system where everybody should be able to key into where it's heading to. I think in terms of integrity in terms of fairness, my colleagues will not score me low. They will not score me low". With the government, they claimed that they interact by paying their dues, obey the laid down rules and regulations and support the supervisory role by the government. One of the participants said he was not sure if he is friendly with the government. "Well concerning government, we interact with the government majorly incommunicado supervisory role. So we don't have so many problems with the government".

Discussion of Findings: The main results show that possessing the competencies; communication and relationship management, leadership and business skills and knowledge do influence the job performance of Physician Mangers. There was a significant difference between physicians that had formal training in management and those that had none in the communication and professionalism domains. Consequently, the findings of the present study are similar to previous studies in the literature (Tandon et al., 2017; Oyekale, 2017; Omaswa, 2014). Specifically, the present study also posits that the Nigerian health care system has been bedeviled with many issues from poor health indices (Tandon et al., 2017), low budgetary allocation (Premium Times, 2017), poorly equipped hospitals (Oyekale, 2017), inadequate and under-motivated personnel (Omaswa, 2014) to disharmony amongst different health professionals particularly over leadership in health institutions (Adindu, 2013). Similar to previous studies, healthcare leadership and management issues were the most common cause of health worker's poor job performance (Oyekale, 2017; Omaswa, 2014). Also, similar to the main findings in Perry et al.'s (2017) study, most physicians in Nigerian are not taught management skills in medical school and receive little on-the-job training to receive such skills.

The present study, therefore, concurs with the main findings of Loh's (2015) study that there were greater benefits in having physicians in management but they required more training in leadership competencies. However, the placement of physicians in managerial roles should not be seen as a design to favor doctors', so as not to compound the present supremacy challenge and the already weak Nigerian health system. It is thus a matter of priority to address the leadership tussle by determining if physicians indeed have what it requires and identify skills lacked to perform well enough to stop the bickering. Furthermore, based on the main findings, the present study, therefore, supports the need for Nigerian physicians to acquire new managerial skills and competencies to meet up current health demands in the country (Eller, 2017). It is therefore pertinent to assess the managerial skill needs of physicians and integrate the findings into the undergraduate and postgraduate medical training curricula in Nigerian tertiary institutions (Ojo \& Akinwunmi, 2015). However, findings from this study differ from previous studies in the literature (Orlando \& Hayataian, 2012; Ackerly et al., 2011).

Specifically, Ackerly et al. (2011) identified a limited need for managerial competencies among physicians but rather focused on nursing managers and physician managers. Contrary to the main findings in the present 
study, Tuong and Thanh (2017) study developed competency models for public hospital managers in Vietnam. Other studies also argue for the necessity to concentrate on the competencies of physicians in different areas such as Palliative care (Pampuri and 2016), Occupational Health (Lalloo et al., 2016), Public Health (Bertoncello et al., 2015), Radiographers (Mung'omba and Botha, 2017) if the desired job performance improvements are to be realized. Also, rather than concentrating on the Physician managers, Dias and Escoval (2014) did a study to examine the demand for new skills and its influence on both innovation investments and the development of new skills in the public hospital sector in Portugal. The study participants were administrators of hospital management boards which included clinical and non -clinical managers and the focus was on organizational rather than individual skills and gaps.

In a similar study, Kalhor et al. (2016) studied the managerial competencies of Hospital managers in Tehran, Iran but unlike that of Dias and Escoval, looked at individual competencies and compared managers in the public and private sectors. A cross-sectional survey using self -administered questionnaires was done. However, a major limitation identified by the authors was that the competencies assessed do not reflect the scope of hospital managers. Pillay (2010) did a similar study comparing the skills of hospital managers in public and private hospitals in South Africa. A self-assessed proficiency in different skills was done. "People management, self-management and task-related skills rated highest with largest deficits for the private sector being people management, self-management and health delivery skills" (Pillay, 2010). This study was not specific for physicians and also lacking in covering all the skills required for performance as a physician manager. Notwithstanding the diverse findings, one common theme in the present study and previous literature is the necessity for improvements in strategic planning, people management and self-management of leaders to improve both workers and organizational performance of health institutions in developing countries (Adindu, 2013; Ochonma \& Nwatu, 2018).

\section{Summary, Conclusion and Policy Recommendations}

Summary and Conclusion: The purpose of this study is to assess the influence of Competencies and Development Needs on the performance of physician managers in Oyo State hospitals. In this chapter conclusions are made based on the results from the analysis and recommendations are made. The majority of the Physician Managers were 46-60years. There were more males than females amongst them and most of them were in the private hospital as Medical Directors with over 10 years of experience in management. Most of the PMs were competent in communication and relationship management, leadership and business skills knowledge. The analysis shows that the least competence was in business skills and knowledge. This goes to show that there is a need for PMs to develop business skills and knowledge. From the data analysis, the importance of management training for physicians was emphasized by all the interview participants. The study, therefore, concluded that possessing the competencies; communication and relationship management, leadership and business skills and knowledge do influence the job performance of Physician Mangers. There was a significant difference between physicians that had formal training in management and those that had none in the communication and professionalism domains. There was no significant association between the experiences of the PMs and their job performance. This suggests that managers arrive at managerial positions without strategic preparation and thus emphasis is not placed on training; formal or informal.

Recommendations and Implications: Physicians have been perceived to be bad managers by other healthcare professionals in Nigeria. This is one of the major causes of disharmony in the health sector leading to incessant strike actions in the health sector. Various studies have shown the need for physicians to be in management positions in hospitals for improved healthcare delivery particularly one that is patient-centered and evidence-based. Some studies have reported better management practices with physicians as managers. Many studies have also reported the ill-preparedness of physicians during their medical training, both at the undergraduate and postgraduate levels for managerial roles with little or no training in management. However, there is limited literature on if Nigerian physicians have the competencies to be managers, what their development needs are and how these affect their performance as physician managers. To be effective and efficient managers, physicians require many skills. However, the key skills they require have been narrowed down into five competency domains by Stefl (2008) in the study on 'Common Competencies of all Healthcare Managers'. The first three research questions on the effect of communication and relationship 
skills, leadership skills and business skills and knowledge of physician managers on their job performance are based on three of these domains.

The literature on competencies of physician managers along these domains was scanty and so was the effect of the competencies on job performance. Most literature reported the need for training in management among physicians but not on the effect this development need has on the job performance hence the need for the research question. The study also recommends the need for physicians to be competent in communication and relationship management skills due to their positive influence on their job performance. A good working relationship with colleagues, other health professionals, the public and even with the government are also necessary. Many respondents considered human resources the most important part of the hospital organization and most intricate; as such the PMs give it the utmost attention. The team-building aspect of the domain was emphasized. More culturally, the importance of getting involved in the social lives of other health professionals e.g. attending a laboratory technician s child dedication also helps with building better work relationships. The respondent PMs from the hospitals in Ibadan city reported they had good leadership qualities. These they demonstrated particularly in the government hospitals where they kept providing healthcare services despite daunting challenges. Leadership among physicians may seem innate as "nearly all physicians take on significant leadership responsibilities throughout their career" (Adindu, 2013; Bocar, 2013). This skill was exhibited in the innovative ways many of the PMs were managing their hospitals with low manpower.

Poor funding, old equipment and dilapidated structures. It may be this trait theory in physicians that resulted in no significant difference in their leadership skills with or with out formal management training. The ability of PMs to provide vision, direction and take decisions in health institutions will boost the confidence of other healthcare professionals in them. PMs have both administrative and clinical responsibilities. Proper management of hospital funds requires business skills and knowledge. Lower competence was reported in this domain compared with the other two domains and invariably lesser job performance too. Some of the PMs employed financial experts to manage hospital accounts. It was the domain of least achievement in the previous year among physicians. Healthcare delivery today is not just about clinical work but business too especially with the emergence of managed care and/ or health insurance. This study identified a skill gap in business administration skills which is vital to PMs. Many PMs also reported a need for ICT training. The need for formal management training was a consensus. However, while some recommended introducing it during undergraduate training, others reported and at different stages of the medical career. Attendance at one or two management training or courses annually should, however, be the rule rather than the exception. Consequently, the following additional recommendations are made for physician managers and policymakers: Physicians in Nigeria need to improve their managerial skills.

Management training should be included in both undergraduate and postgraduate curricula. It should be a requirement for promotion in management in the hospital; there is a need to develop a Nigerian competency framework for assessing physician managers' competencies; Physician managers should be a manager to all health professionals, not physicians only. Teamwork and collaboration should be encouraged at all times; Physicians in management need to keep abreast of political happenings and policies regarding the healthcare industry. This study has provided a better understanding of the competencies and development needs of physicians in managerial positions in Nigeria. This study is currently the only one that provides information on the competencies and development needs of physician managers only. This study is also the only one currently that has assessed physician managers using a standard, internationally acceptable tool; the Health Alliance Competency directory. The time available for the study was short. Ethical approval took longer than anticipated.

The busy schedules of health executives made many turn down participation and some even though they accepted to participate failed to fill the questionnaire despite several reminders. A few physicians in the private sector out rightly declined participation saying "I do not take part in research" and another "speak to my matron, she can answer all your questions". Moving around a big city like Ibadan was also timeconsuming and tiring. Self-evaluation using the survey is subjective. However, the time available for the study was short. The busy schedules of health executives made many turn down participation and some even though they accepted to participate failed to fill the questionnaire despite several reminders. Moving around 
a big city like Ibadan was also a challenge. Consequently: 1 . There is a need for further research into the appraisal of physicians for management positions, particularly how personal qualities can affect this, 2 . More information on what influences a physician into management, 3. Investigate why other health professionals perceive physicians as bad managers and why they believe they are better managers, 4 . There is little research on the patient s perception of the physician as the manager.

\section{References}

Ackerly, D. C., Sangvai, D. G., Udayakumar, K., Shah, B. R., Kalman, N. S., Cho, A. H., Schulman, K. A., Fulkerson, W. J. \& Jr, Dzau, V. J. (2011). Training the next generation of physician-executives: an innovative residency pathway in management and leadership, Acad Med, 86(5), 575-579.

Adindu, A. (2013). Management Training and Health Managers Perception of Their Performance in Calabar, Nigeria. Quality Management in Health, 16(4), 14-19.

Armstrong, S. J., Rispel, L. C. \& Penn-Kekana, L. (2015). The activities of hospital nursing unit managers and quality of patient care in South African hospitals: a paradox? Glob Health Action, 8(10), 340-342.

Awolusi, O. D. (2019). Human Capital Development and Economic Growth in BRICS Countries: Controlling for Country Differences, Journal of Economics and Behavioral Studies, 11(4), 1-17.

Awolusi, O. D. \& Atiku, O. S. (2019). Business Process Re-Engineering and Profitability in the Nigerian Oil and Gas Industry: The Mediating Influence of Operational Performance, Information Management and Business Review, 11(3), 13-26.

Bax, M. F. P., Berkenbosch, L. \& Busari, J. O. (2011). How do medical specialists perceive their competency as physician managers? International Journal of Medical Education, 2(1), 133-139.

Bertoncello, C., Buja, A., Silenzi, A., Specchia, M. L., Franchino, G., Lazzari, A., Baldo, V. Ricciardi, W. \& Damiani, G. (2015). Good governance competencies in public health to train public health physicians, Int J Public Health, 60(6), 737-749.

Berg, B. L. \& Howard, L. (2012). Qualitative Research Methods for the Social Sciences. (8thed). USA: Pearson Educational Inc.

Bocar, A. C. (2013). Difficulties Encountered by the Student-Researchers and the Effects on their Research Output, Proceedings of the Global Summit on Education, 11-12.

Busari, J. O., Berkenbosch, L. \& Brouns, J. W. (2011). Physicians as managers of health care delivery and the implications for postgraduate medical training: a literature review. Teach Learn Medicine, 23(2), 18696.

Campbell, K. R. (2012). The Importance of Physician Leaders in Medicine Today: Blazing a Trail to Better Healthcare. Available at https://drkevincampbellmd.wordpress.com/.../the-importance-ofphysician-leaders-in-..Accessed 26/9/17

Charan, J. \& Biswas, T. (2013). How to Calculate Sample Size for Different Study Designs in Medical Research? Indian Journal of Psychological Medicine, 35(2), 121-126.

Clay-Williams, R., Ludlow, K., Testa, L., Li, Z. \& Braithwaite, J. (2017). Medical leadership, a systematic narrative review: do hospitals and healthcare organizations perform better when led by doctors?

Dias, V. \& Escoval, A. (2014). Narrowing the Skills Gap for Innovation: An Empirical Study in the Hospital Sector. JMIR Human Factors, 1(1), 23-34.

Donald, D. U. (2013). Challenges of Clinical Leadership in Nigeria. Journal of Psychiatry, 18(1), 210-220.

Dworkin, S. L. (2012). Sample Size Policy for Qualitative Studies Using In-Depth Interviews, Archives of Sexual Behavior, 41(6), 1319-1320.

Eller, A. L. (2017). Medical Education needs management training.KevinMD.com. Available Atwww.kevinmd.com/blog/2017/.../medical-education-needs-management-training.html. Accessed $27 / 9 / 17$

Feigenbaum, E. (2017). Theories of Healthcare Management. Available at https://healthyliving.azcentral.com $>$ Diet \& Nutrition > Nutrition. Accessed 26/7/18.

Fitzell, J. (2015). Assessing Your Development Needs. Professionals in Australia. www.professionalsaustralia.org.au/blog/assessing-your-development-needs/(Accessed 25/7/18)

Goodall, A. H. (2011). Physician Leaders and hospital Performance: Is there an Association? Social Science and Medicine, 73(4), 535-539. 
Goodall, A. H., Bastiampillai, T., Nance, M., Roeger, L. \& Allison, S. (2015). Expert leadership: Doctors versus managers for the executive leadership of Australian mental health. Aust New Zeal J Psychiatry, 49(1), 409-411.

Hassan J. (2013). JOHESU strike: issues, resolution and lessons' Daily Independent (online). Posted in:

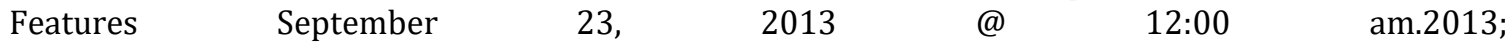
http://www.dailyindependentnig.com/2013/09/johesu-strike-issues-resolutions-and-lessons/. Accessed 3 July 2018

Hospitals Management Board. (2017). Oyo State Government. Available https://oyostate.gov.ng/hospitalmanagement-board/. Accessed 25/8/18

Ibeh, N. (2015). Nigerian health workers call off strike' Premium Times. 2015; http://www.premiumtimesng.com/news/top-news/176152-nigerian-health-workers-call-offstrike.html. Accessed 10 Apr 2015.

Ireri, S. K., Walshe, K., Benson, L. \& Mwanthi, M. (2017). A Comparison of Experiences, Competencies And Development Needs of Doctor Managers in Kenya and the United Kingdom. The International Journal of Health Planning and Management, 2(4), 509-539.

Johnson, B. \& Christensen, L. (2012). Educational Research, Qualitative, Quantitative and Mixed Approach. (4th ed). California: SAGE Publication.

Jackson, S. L. (2009). Research Methods and Statistics: A Critical Thinking Approach $3^{\text {rd }}$ edition. Belmont, CA: Wadsworth

Kalhor, R. I., Tajnesaei, M., Kakemam, E., Keykaleh, M. S. \& Kaldor, L. (2016). Perceived hospital managerial competency in Tehran, Iran: is there a difference between public and private hospitals? Journal of the Egyptian Public Health Association, 91(4), 157-162.

Kutlu, G. \& Akbulut, Y. (2018). Attitudes towards female managers in hospitals: A case study of Turkey. International Journal of Healthcare Management. https://doi.org/10.1080/20479700.2018.1498219

Lalloo, D., Demou, E., Kiran, S., Cloren, M., Mendes, R. \& Macdonald, E. B. (2016). International perspective on common core competencies for occupational physicians: a modified Delphi study, Occup Environ Med, 73(7), 452-458.

Leedy, P. \& Ormrod, J. E. (2014). Practical Research Planning and Design. (10th ed). Edinburgh: Pearson Educational Inc.

Liu, Z., Tian, L., Chang, Q., Sun, B. \& Zhao, Y. (2016). A Competency Model for Clinical Physicians in China: A Cross-Sectional Survey. PLOS One https://doi.org/10.1371/journal.pone.0166252

Loh, E. (2015). Doctors as health managers: an oxymoron, or a good idea? Journal of Work- Applied Management, 7(1), 52-60.

Lomgurum, M. T. \& Godowoli, A. H. (2008). The Nature of competition and conflicts among Health Professionals in Nigeria. Nigerian Hospital Practice, 2(2), 42-48.

Matira, K. M. \& Awolusi, O. D. (2020). Leaders and Managers Styles towards Employee Centricity: A Study of Hospitality Industry in the United Arab Emirates, Information Management and Business Review, 12(1), 1-21.

Mukonga, L. M. \& Awolusi, O. D. (2019). Strategic Leadership in the Post-Conflict States: A Study of the Democratic Republic of Congo (DRC), Journal of Social and Development Sciences, 10(4), 36-51.

Mung'omba, B. \& Botha, A. D. H. (2017). Core competencies of radiographers working in rural hospitals of KwaZulu-Natal, South Africa. Afr J Prim Health Care Fam Med, 9(1), 1389-1399.

Munyewende, P. O., Levin, J. \& Rispel, L. C. (2016). An evaluation of the competencies of primary health care clinic nursing managers in two South African provinces. Global Health Action, 9(1), 23-34.

Moka, O. O. \& Ajijola, O. (2017). Government hospital management structure and the challenges of industrial disharmony in Nigeria. Journal of Business Administration and Management Sciences Research, 6(2), 25-32.

Motowidlo, S. J. \& Kell, H. J. (2012). Handbook of psychology, vol. 12: Industrial and organizational psychology edition: $2^{\text {nd }}$ Chapter: Job performance.Publisher: WileyEditors: Neal W. Schmitt, Scott High house.

Nigeria Health Watch. (2015). How strikes are killing the Public Healthcare Sector and why it may be difficult to reclaim. https://nigeriahealthwatch.com > Africa

Obi P. (2014). Breaking News...At last, NMA calls off strike' This Day Live. 2014; http://www.thisdaylive.com/articles/breaking-news-at-last-nma-calls-off-strike/187230/.Accessed 3 July 2018. 
Obinna, O. O., Iheaka, P. Z., Olabisi, O., Ezinne, P. A., Deborah, U. \& Simon, D. T. (2016). Industrial action by healthcare workers in Nigeria in 2013-2015: an inquiry into causes, consequences and control-a cross-sectional descriptive study. Human Resources for Health, 14(4), 63-74.

Ochonma, O. G., Nwankwor, C. A., Henry-Arize, I., Igwe, S. E., Nwodoh, C. O., Ingwu, J. A. Ani, G. J. \& Dyages, E. O. (2018). Managerial Competency among Hospital Managers: Does Experience on the Job Matter? International Journal of Social Sciences and Management Research, 4(3), 2545-2560.

Ochonma, O. G. \& Nwatu, S. I. (2018). Assessing the predictors for training in management amongst hospital managers and chief executive officers: a cross-sectional study of hospitals in Abuja, Nigeria. BMC Med Educ, (18), 138. DOI: 10.1186/s12909-018-1230-2.

Odunlami, S. A., Awosusi, O. O. \& Awolusi, O. D. (2017). The Influence of Leadership Styles on Employees' Performance: A study of Selected Private Universities in Ogun State, Nigeria, Global Journal of Commerce and Management Perspective, 6(2), 5-13.

Ojo, T. 0. \& Akinwunmi, A. F. (2015). Doctors as managers of healthcare resources in Nigeria: Evolving roles and current challenges. Nigerian Medical Journal, 56(6), 375- 380.

Oladejo, M. J. \& Awolusi, O. D. (2017). Effect of Work-Family Role Conflicts on Employees' Commitment and Organisational Performance: A study of AKLAD Interlink concept, Nigeria, Global Journal of Commerce and Management Perspective, 7(2), 81-96.

Olatunji S. (2013). Resident doctors begin warning strike on Wednesday' The Punch Newspaper June 25 (online). 2013; http://www.punchng.com/news/resident-doctors-begin-warning-strike-onwednesday/.Accessed 3 July 2018.

Olatunji, O. O. \& Awolusi, O. D. (2019). Performance Evaluation and Improvement among Salesmen in the Nigerian Fast Moving Consumer Goods Sector, Journal of Social and Development Sciences, 10(4), 1229.

Oleribe, O. O., Ezieme, I. P., Oladipo, O., Akinola, P. E., Udofia, D. \& Taylor- Robinson, S. D. (2016). Industrial action by healthcare workers in Nigeria 92018in 2013-2015: an inquiry into causes, consequences and control-a cross-sectional descriptive study. Journal of Human Resources for Health, 14(4), 6271.

Okonkwo, U., Ekpeyoung, B., Ndep, A., Nja, G. \& Adindu, A. (2018). Managerial Competencies- a survey of healthcare managers in a tertiary hospital in Calabar, south-south, Nigeria. Masters in Health Services Management. The University of Calaber. Nigeria.

Olopade, F. E., Adaramoye, O. A., Raji, Y., Fasola, A. O. \& Olopade- Olaopa, E. O. (2016). Developing a competency-based medical education curriculum for the core basic medical sciences in an African medical school. Advances in Medical Education and Practice, 7(1), 389-398.

Omaswa, F. (2014). Solutions for Africa s Health Workforce Crisis through Country Based Research. Human resources for Health, 12(1), 11-23.

Orlando, R. \& Haytaian, M. (2012). Physician leadership: a health-care system's investment in the future of quality care. Conn Med, 76(7), 417-420.

Oyekale, A. S. (2017). Assessment of primary health care facilities' service readiness in Nigeria, Biomedcentral Health Services Research, 17(1), 172-186.

Pampuri, O. \& Zotaj, H. (2016). Competencies of physicians in management and leadership for a better palliative care treatment. Annals of Oncology, 27(6), 1-23.

Perry, J., Mobley, F. \& Brubaker, M. (2017). Most Doctors have little or No Management Training, and that's a problem. Harvard Business Review, 34(1), 345-352.

Pfeffer, J. \& Sutton, R. I. (2006). Evidence-Based Management. Harvard Business Review Pharmaceutical Society of Nigeria (PSN) Tasks FG on Harmonisation of the Health Sector, NHIS Says Medical Doctors are Bad Managers.

Phibbs, B. (2013). 6 Skills Every Small Business Manager Needs to Success. Master card Biz. Available at https://www.mastercardbiz.com > Posts > Security. Accessed 13/9/17

Pillay. (2010). Managerial Competencies of Hospital Managers in South Africa: A Survey of Managers in the Public and Private Sectors. Human Resouces for Health, 7(1), 23-34.

Pillay, R. (2008). Managerial Competencies of hospital managers in South Africa: a survey of managers in the public and private sectors. Human Resources for Health, 6(4), 23-34.

Premium Times. (2014). Fresh strike looms as doctors warn the Nigerian government Premium Times. 2014; http://www.premiumtimesng.com/news/157478-fresh-strike-looms-doctors-warn-nigeriangovernment.html.Accessed 3 July 2018. 


\section{Journal of Social and Development Sciences (ISSN 2221-1152)}

Vol. 12, No. 2, pp. 1-19, June 2021

Robinson Olokor, F. (2013). NMA suspends warning strike' The Punch Newspaper.2013; http://www.punchng.com/news/nma-suspends-warning-strike/.Accessed 3 July 2018.

Sarto, F., Veronesi, G., Kirkpatrick, I. \& Cuccurullo, C. (2014). Clinicians in Governance: Evidence for Hospital Performance from the Italian NHS. In XVIII ISA World Congress of Sociology Proceedings.

Schram, R. (1971). A History of Nigerian Health Care Services. Ibadan University Press, Ibadan

Sonsale, A. \& Bharamgouder, R. (2017). Equipping future doctors: incorporating management and leadership into medical curriculums in the United Kingdom.

Spehar, I., Frich, J. C. \& Kjekshus, L. E. (2012). Clinicians' experiences of becoming a clinical manager: a qualitative study. BMC Health Services Research, 12(1), 421-429.

Stefl, M. E. (2008). Common Competencies for All Healthcare Managers: The Healthcare Leadership Alliance Model. J Health Manag, 53(6), 360-73.

Stoller, J. K., Goodall, A. \& Baker, A. (2016). Why The Best Hospitals Are Managed by Doctors. Harvard Business Review, 23(1), 23-36.

Tandon, A., Murray, C. J. L., Lauer, J. A. \& Evans, D. B. (2017). Measuring Overall Health System Performance for 191 Countries. World Health Organisation.

Tlaiss, H. A. (2013). Women in healthcare: barriers and enablers from a developing country perspective. International Journal on Health Policy Management, 13(1), 23-33.

Tuong, P. V. \& Thanh, N. D. (2017). A Leadership and Managerial Competency Framework for Public Hospital Managers in Vietnam, AIMS Public Health, 4(4), 418-429.

Veronesi, G., Kirkpatrick, I. \& Vallascas, F. (2014). Does clinical management improve efficiency? Evidence from the English National Health Service. Public Money Manag, 34(1), 35-41. 